\title{
First Experience in Clinical Application of KANET
}

\author{
Ana Tikvica Luetic
}

\begin{abstract}
Introduction of three- and four-dimensional ultrasound into clinical practice enabled qualitative and quantitative assessment of fetal movements, including the analysis of fetal face expression which is considered to be the mirror of the maturational processes of upper motor neuron. Since, prenatal fetal behavioral patterns are reflections of developmental and maturational processes within the fetal central nervous system, the findings about changes in fetal movements and behavior could leed to the prenatal diagnosis of neurological impairment. Kurjak's antenatal neurodevelopment test (KANET) is the first prenatal test based on the three- and four-dimensional ultrasound examination of the fetus that could be used for the evaluation and prediction of the fetal neurologic status.
\end{abstract}

Keywords: Fetal behavior, Three/four-dimensional ultrasound, KANET.

How to cite this article: Luetic AT. First Experience in Clinical Application of KANET. Donald School J Ultrasound Obstet Gynecol 2015;9(1):96-99.

\section{Source of support: Nil}

Conflict of interest: None declared.

The goal of assessing fetal behavior and predicting its neonatal and even adult neurological development exists among clinicians for a long period of time. One way to monitor fetal behavior is to count fetal body movements which are done by the mother and then analyze by her medical professional. This method is well-accepted since fetal movements are considered as indicator of fetal health and it is widely used in everyday practice since it is pretty simple and easy to perform. Although, fetal movement counting or so-called kick counting could be used as primary screening method to assess fetal health, this technique has many limitations such as the fact that optimal number of movements and the ideal duration of counting have not yet been recognized. Another disadvantage is certain lack of sensitivity because mother is not always conscious about the fetal movements. A

\footnotetext{
Assistant Professor

Department of Obstetrics and Gynecology, Clinical Hospital 'Sveti Duh', Zagreb, Croatia
}

Corresponding Author: Ana Tikvica Luetic, Assistant Professor Department of Obstetrics and Gynecology, Clinical Hospital 'Sveti Duh', Sveti Duh 64, 10000 Zagreb, Croatia, e-mail: ana_tikvica@ yahoo.com definitive step through in fetal movement assessment was made with the development of two-dimensional ultrasound (2D US) which enabled direct visualization of fetal anatomy and activity. With the possibility of ultrasound assessment of fetal movements, many researchers started to investigate fetal behavior with results that were compared to morphological studies and revealed that fetal behavioral patterns are reflections of developmental and maturational processes within the fetal central nervous system. These findings were encouraging for the hypothesis that changes in fetal movements and behavior could be used for the prenatal diagnosis of neurological impairment. ${ }^{1-4}$ Ultrasound evaluation of fetal body movements has previously been integrated in a test of fetal well-being and assessing fetal biophysical profile (BPP). This is a more objective method of fetal movements analysis as compared to fetal movement counting by the mother and it is a combination of prenatal ultrasound evaluation and fetal heart rate monitoring involving a scoring system with the score being termed as Manning's score. ${ }^{5}$ Although BPP could be sufficiently used as a method of fetal surveillance and prediction of acute or chronic fetal hypoxia its utility in assessing fetal neurobehavioral condition is quite limited.

Two-dimensional ultrasound has technical limitations since it enables only quantitative assessment of fetal body movements, while three- and four-dimensional ultrasound (3D/4D US) adds the possibility of further qualitative assessment of fetal and even embryonic movements, including complexity and variability. ${ }^{6-14}$ Furthermore, 3D/4D US can be used for the analysis of fetal face expression that is significant for the maturational processes of upper motor neuron. ${ }^{15}$

Neurological evaluation of neonates can be done by using Amiel-Tison neurologic assessment at term with scoring system and complete procedure that takes approximately 5 minutes. ${ }^{16}$ This test was used as a model for creating prenatal neurologic assessment test due to its utility, effectivity and simplicity in performing it. Another stimulation in creating prenatal test was the finding that there is a continuity from fetal to neonatal behavior, in terms of all facial and hand movements directed to the head, while the Moro reflex was present only in neonates. ${ }^{17}$ 3D and 4D US evaluation of fetal and embryonic movements have shown that the repertoire and frequency of fetal movement patterns constantly 
expand, whereas the second and third trimesters are characterized by the progressive organization of fetal activities into complex and clearly distinct behavioral patterns. ${ }^{18-25}$ These first 3D and 4D ultrasound studies were used for the establishment of the normal standards of fetal behavioral patterns that are necessary for the distinction between normal and abnormal fetal behavior. ${ }^{20}$ Since, there is substantial evidence to show that many neurological problems, from minor cerebral dysfunction to the cerebral palsy, originate from the prenatal, rather than perinatal or postnatal periods of life it could be of great importance the possibility of prenatal detection or prediction of the cerebral palsy. ${ }^{26}$

The idea of prenatal assessment of fetal behavior was first based on the presumption that a differences in fetal motility could be found between normal and abnormal pregnancies and that changes in fetal behavior could lead to the conclusion about the impaired prenatal neurological development and even postnatal sequel. Abnormal motor behavior assessed by 3D and 4D was prenatally described in anencephalic fetus ${ }^{27}$ and later in a group of growth restricted fetuses for whom it has been shown to have less behavioral activity than normal fetuses in all observed movement patterns. ${ }^{28}$ The potential diagnosis of impaired fetal behavior could also be established in different pathological conditions of pregnancies such as gestational diabetes, different infections and even in pregnancies with previous children affected by cerebral palsy. ${ }^{29,30}$ Kurjak et al showed the improvement in fetal movement assessment by 3D and 4D US as compared to $2 \mathrm{D}$ in normal and high risk pregnancies. ${ }^{6-14}$ In order to enable more objective evaluation of fetal movements and the comparison among different professionals and centers these group of authors came up with the new scoring system for fetal neurobehavioral based on prenatal assessment of fetal movements by 3D/4D sonography. ${ }^{31,32}$ As a first step in creating the test its results were compared to postnatal neurological assessment and the positive correlation has been determined in the low-risk and high-risk pregnancies as well. This preliminary work was assigned as very important in detecting fetal brain and neurodevelopmental alterations due to in utero brain impairment. ${ }^{31}$ This new test was called Kurjak's antenatal neurodevelopment test (KANET) and it is the first structured and systematic test that used 4D US technology to assess the functional development of the central nervous system of the fetus in a similar way that neonates are examined postnatal for brain damage by neonatal neurological tests. ${ }^{31}$ The parameters included in KANET are combination of general movements and parameters that have already shown to be sufficient in ATNAT such as overlapping sutures and neurological thumb. ${ }^{31}$ The KANET test was standardized in Osaka, Japan on the 24th of October 2010, in order for the test to become more sufficient, reproducible and applicable by fetal medicine specialists. ${ }^{33}$ According to the Osaka Consensus Statement the KANET should be performed in the 3rd trimester of pregnancy, between 28 and 38 weeks and fetuses should be examined while they are awake. If the fetus is in the sleeping period, the assessment should be postponed for 30 minutes or for the following day, at a minimum period of 14 to 16 hours. Studies dealing with the use of KANET in normal pregnancies have shown that a normal prenatal KANET score is significantly predictive of normal postnatal neurological outcome, ${ }^{34}$ while infants with abnormal or borderline KANET should be submitted to postnatal follow-up. ${ }^{35-39}$

The KANET test should be performed by licensed professionals using a four-dimensional ultrasound (4D US). At our department the exposure time per patient is always on the investigator' $\mathrm{s}$ mind the duration of examinations rarely exceeds 20 minutes and it is never longer than 30 minutes according to the internal ethical approval of the Institution. Patients are always explained in details about the nature and possible findings of the test and the compliance is always good since the examination is always followed by the display of good three and four-dimensional ultrasound pictures of the fetus to the future mother. All parameters of the KANET scoring system are evaluated quantitatively and qualitatively, assigning to each parameter scores from 0 to 2 . Scores from all parameters are summarized forming a total KANET score. In cases of abnormal or of borderline score, the test is repeated every 2 weeks until delivery while all the infants examined by the KANET are followed up by our neonatologists and pediatricians to the age of 14 .

At our department KANET has already been introduced in everyday clinical practice as a reproducible and sensitive prenatal screening neurological test. The results of KANET are still analyzed in comparison with postnatal neurologic follow-up but we hope that our results combined with numerous other ongoing studies will answer the questions about statistical value of the test and will help the introduction of the KANET as widely accepted prenatal assessment of fetal neurobehavior.

\section{REFERENCES}

1. Ferrari F, Cioni G, Prechtl HF. Qualitative changes of general movements in preterm infants with brain lesions. Early Hum Dev 1990 Sep;23(3):193-231.

2. Prechtl HFR. Qualitative changes of spontaneous movements in fetus and preterm infant are a marker of neurological dysfunction. Early Hum Dev 1990;23(3):151-158. 
3. Hadders-Algra M. General movements: a window for early, identification of children at high-risk of developmental disorders. J Pediatr 2004;145:S12-18.

4. Amiel-Tison A, Gosselin J, Kurjak A. Neurosonography in the second half of fetal life: a neonatologist's point of view. J Perinat Med 2006;34(6):437-446.

5. Manning FA. Fetal biophysical profile. Obstet Gynecol Clin North Am 1999 Dec;26(4):557-577.

6. Stanojevic M, Kurjak A, Andonotopo W. Assessment of fetal to neonatal behavioral continuity by $4 \mathrm{D}$ ultrasonography. Ultrasound Obstet Gynecol 2006;28(3):360.

7. Miskovic B, Vasilj O, Stanojevic M, Ivankovic D, Kerner M, Tikvica A. The comparison of fetal behavior in high-risk and normal pregnancies assessed by four-dimensional ultrasound. J Matern Fetal Neonatal Med 2010 Dec;23(12): 1461-1467.

8. Abo-Yaqoub S, Kurjak A, Mohammed AB, Shadad A, AbdelMaaboud M. The role of 4-D ultrasonography in prenatal assessment of fetal neurobehaviour and prediction of neurological outcome. J Matern Fetal Neonatal Med 2012;25(3): 231-236.

9. Kuno A, Akiyama M, Yamashiro C, Tanaka H, Yanagihara T, Hata T. Three-dimensional sonographic assessment of fetal behavior the early second trimester of pregnancy. J Ultrasound Med 2001 Dec;20(12):1271-1275.

10. Kurjak A, Carrera JM, Stanojevic M, Andonotopo W, Azumendi G, Scazzocchio E, Medic E, Salihagic-Kadic A. The role of $4 \mathrm{D}$ sonography in the neurological assessment of early human development. Ultrasound Rev Obstet Gynecol 2004 Sep;4(2):148-159.

11. Kurjak A, Luetic AT. Fetal neurobehavior assessed by threedimensional/four dimentional sonography. Zdrav Vestn 2010;79:790-799.

12. Kurjak A, Miskovic B, Andonotopo W, Stanojevic M, Azumendi G, Vrcic H. How useful is 3D and $4 \mathrm{D}$ ultrasound in perinatal medicine? J Perinat Med 2007;35(1):10-27.

13. Kurjak A, Pooh R, Tikvica A, et al. Assessment of fetal neurobehavior by 3D/4D Ultrasound Fetal Neurology 2009: 222-250.

14. Andonotopo W, Stanojevic M, Kurjak A, Azumendi G, Carrera JM. Assessment of fetal behavior and general movements by four-dimensional sonography. Ultras Rev Obstet Gynecol 2004;4(2):103-108.

15. Kurjak A, Azumendi G, Andonotopo W, Salihagic-Kadic A. Three-and four-dimensional ultrasonography for the structural and functional evaluation of the fetal face. Am J Obstet Gynecol 2007 Jan;196(1):16-28.Epub 2006 Oct 2.

16. Amiel-Tison C. Update of the Amiel-Tison neurologic assessment for the term neonate or at 40 weeks corrected age. Pediatr Neurol 2002 Sep;27(3):196-212.

17. Kurjak A, Stanojevic M, Andonotopo W, Salihagic-Kadic A, Carrera JM, Azumendi G. Behavioral pattern continuity from prenatal to postnatal life-a study by four-dimensional (4D) ultrasonography. J Perinat Med 2004; 32(4): 346-353.

18. Kurjak A, Carrera J, Medic M, Azumendi G, Andonotopo W, Stanojevic M. The antenatal development of fetal behavioral patterns assessed by four-dimensional sonography. J Matern Fetal Neonatal Med 2005 Jun;17(6):401-416.
19. Kurjak A, Stanojevic M, Andonotopo W, Scazzocchio-Duenas E, Azumendi G, Carrera JM. Fetal behavior assessed in all three trimesters of normal pregnancy by four-dimensional ultrasonography. Croat Med J 2005 Oct;46(5):772-780.

20. Kurjak A, Andonotopo W, Hafner T, Salihagic Kadic A, Stanojevic M, Azumendi G, Ahmed B, Carrera JM, Troyano JM. Normal standards for fetal neurobehavioral developments-longitudinal quantification by four-dimensional sonography. J Perinat Med 2006;34(1):56-65.

21. Stanojevic M, Kurjak A. Continuity between fetal and neonatal neurobehavior. Donald School J Ultrasound Obstet Gynecol 2008;2(2):64-75.

22. Stanojevic M, Zaputovic S, Bosnjak AP. Continuity between fetal and neonatal neurobehavior. Semin Fetal Neonatal Med 2012 Dec;17(6):324-329.

23. Stanojevic M, Kurjak A, Salihagic-Kadic A, Vasilj O, Miskovic B, Shaddad AN, Ahmed B, et al. Neurobehavioral continuity from fetus to neonate. J Perinat Med 2011;39(2):171-177.

24. Kurjak A, Tikvica Luetic A, Stanojevic M, Talic A, Zalud I, AlNoobi M, et al. Further experience in the clinical assessment of fetal neurobehavior. Donald School J Ultrasound in Obstet Gynecol 2010;4:59-71.

25. Predojevic M, Stanojevic M, Vasilj O, Kadic AS. Prenatal and postnatal neurological evaluation of a fetus and newborn from pregnancy complicated with IUGR and fetal hypoxemia. J Matern Fetal Neonatal Med 2011;24(5):764-767.

26. Salihagic-Kadic A, Kurjak A, Medic M, Andonotopo W, Azumendi G. New data about embryonic and fetal neurodevelopment and behavior obtained by 3D and 4D sonography. J Perinat Med 2005;33(6):478-490.

27. Andonotopo W, Kurjak A, Kosuta MI. Behavior of an anencephalic fetus studied by $4 \mathrm{D}$ sonography. J Matern Fetal Neonatal Med 2005 Feb;17(2):165-168.

28. Andonotopo W1, Kurjak A. The assessment of fetal behavior of growth restricted fetuses by $4 \mathrm{D}$ sonography. J Perinat Med 2006;34(6):471-478.

29. Talic A, Kurjak A, Ahmed B, Stanojevic M, Predojevic M, Kadic AS, Di Renzo GC. The potential of 4D sonography in the assessment of fetal behavior in high-risk pregnancies. J Matern Fetal Neonatal Med 2011 July;24(7):948-954.

30. Kurjak A, Abo-Yaqoub S, Stanojevic M, Yigiter AB, Vasilj O, LebitD, Shaddad AN, Ahmed B, Kavak ZN, Miskovic B, et al. The potential of $4 \mathrm{D}$ sonography in the assessment of fetal neurobehavior-multicentric study in high-risk pregnancies. J Perinat Med 2010;38(1):77-82.

31. Kurjak A, Miskovic B, Stanojevic M, et al. New scoring system for fetal neurobehavior assessed by three- and four-dimensional sonography. J Perinat Med 2008;36(1): 73-81.

32. Kurjak A, Ahmed B, Abo-Yaquab S, Younis M, Saleh H, Shaddad AN, Vasilj O, Al Bahar AJ, Miskovic B, Khenyab N. An Attempt to Introduce Neurological Test for Fetus Based on 3D and 4D Sonography Donald School J Ultrasound Obstet Gynecol 2008;2(2):29-34.

33. Stanojevic M, Talic A, Miskovic B, Vasilj O, Shaddad AN, Ahmed B, Kadic AS, Predojevic M, Vladareanu R, AbuYaqoub DLS, Al-Noobi M. An attempt to standardize Kurjak's antenatal neurodevelopmental test: Osaka Consensus Statement. DSJUOG. 2011 Oct-Dec;5:p. 317-329. 
34. Honemeyer U, Kurjak A. The use of KANET test to assess fetal CNS function. First 100 cases. 10th World Congress of Perinatal Medicine 8-11 November 2011. Uruguay. Poster Presentation p 209.

35. Athanasiadis AP, Mikos T, Tambakoudis GP, Theodoridis TD, Papastergiou M, et al. Neurodevelopmental fetal assessment using KANET scoring system in low and high risk pregnancies. J Matern Fetal Neonatal Med 2013;26(4):363-368.

36. Talic A, Kurjak A, Stanojevic M, Honemeyer U, Badreldeen A, Direnzo GC. The assessment of fetal brain function in fetuses with ventrikulomegaly: the role of the KANET test. J Matern Fetal Neonatal Med 2012 Aug;25(8):1267-1272.
37. Honemeyer U, Talic A, Therwat A, Paulose L, Patidar R. The clinical value of KANET in studying fetal neurobehavior in normal and at-risk pregnancies. J Perinat Med 2012 Sep 28;0(0):1-11.

38. Kurjak A, Talic A, Honemeyer U, Stanojevic M, Zalud I. Comparison between antenatal neurodevelopmental test and fetal Doppler in the assessment of fetal well being. J Perinat Med 2013 Jan;41(1):107-114.

39. Predojevic M, Talic A, Stanojevic M, Kurjak A, Salihagic Kadic A. Assessment of motoric and hemodynamic parameters in growth restricted fetuses—case study. J Matern Fetal Neonatal Med 2013 Jun 20. 